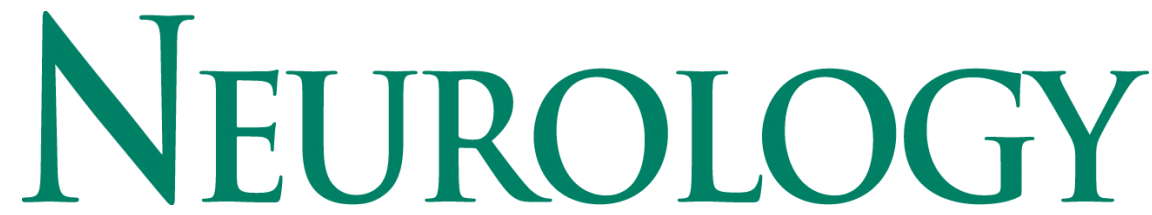

A genome-wide scan and HCRTR2 candidate gene analysis in a European cluster headache cohort

L. Baumber, C. Sjöstrand, M. Leone, H. Harty, G. Bussone, J. Hillert, R. C. Trembath and M. B. Russell

Neurology 2006;66;1888-1893

DOI: 10.1212/01.wnl.0000219765.95038.d7

This information is current as of June 29, 2006

The online version of this article, along with updated information and services, is located on the World Wide Web at:

http://www.neurology.org/cgi/content/full/66/12/1888

Neurology is the official journal of AAN Enterprises, Inc. A bi-monthly publication, it has been published continuously since 1951 . Copyright $(2006$ by AAN Enterprises, Inc. All rights reserved. Print ISSN: 0028-3878. Online ISSN: 1526-632X.

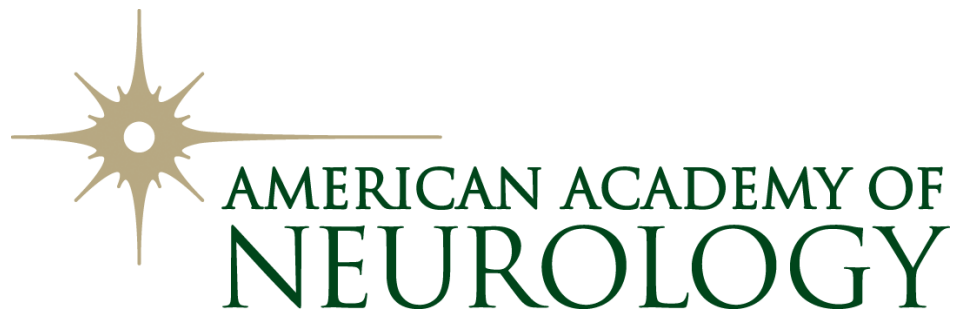




\title{
औich A genome-wide scan and HCRTR2 candidate gene analysis in a European cluster headache cohort
}

\author{
L. Baumber, BSc; C. Sjöstrand, MD; M. Leone, MD; H. Harty, BSc; G. Bussone, MD; J. Hillert, MD, PhD; \\ R.C. Trembath, BSc, FRCP; and M.B. Russell, MD, PhD, DMSci
}

\begin{abstract}
Objective: To investigate the molecular genetic basis of cluster headache (CH), using a genome-wide scan and candidate gene strategy. Methods: Northern European $\mathrm{CH}$ families and a case-control cohort of Danish, Swedish, and British origin (total $n=259$ sporadic $\mathrm{CH}$ patients), including 267 control subjects matched for ancestry, participated in the study. A genome-wide genetic screen using approximately 400 microsatellite markers was performed for five informative Danish $\mathrm{CH}$ families. Additional markers were typed for those loci generating statistical evidence suggestive of linkage, together with genotypes for 111 individuals from further Danish and Italian kindreds. Sporadic $\mathrm{CH}$ patients and controls were investigated by association analysis for variation in the candidate gene, HCRTR2. Finally, complete HCRTR2 sequencing was undertaken for eight independent probands. Results: Potential linkage was identified at four possible disease loci in Danish kindreds, yet no single chromosome location generated a lod or NPL score of recognized significance. No deleterious sequence variants of the HCRTR2 gene were detected by comparison to wild-type sequence. Association of the HCRTR2 gene was not replicated in this large dataset, even when the data were stratified into distinct populations. Conclusions: Cluster headache is a complex genetic disorder, with possible phenotypic and genetic heterogeneity compounding attempts at gene identification.
\end{abstract}

NEUROLOGY 2006;66:1888-1893

Cluster headache $(\mathrm{CH})$ is characterized by unilateral, periodic attacks of excruciating pain, accompanied by autonomic dysfunction. ${ }^{1,2}$ In $<10 \%$ of patients, chronic $\mathrm{CH}$ features persist. ${ }^{3}$ The disease has an estimated prevalence of $1 / 500,,^{4-6}$ and displays marked sex bias (female:male ratio $<1: 2.5$ to 3.5 ). ${ }^{1,7,8}$ $\mathrm{CH}$ is considered to be a neurovascular disorder with activation of hypothalamic, trigeminovascular, and cranial parasympathetic systems. ${ }^{9,10}$ Altered neurohormone levels ${ }^{11-14}$ indicate central activation, and PET studies reveal ipsilateral inferior hypothalamic gray matter changes during attacks. ${ }^{10,15}$ Pain relief by deep brain stimulation of the posterior hypothalamus further implicates central activation processes in disease pathogenesis. ${ }^{16,17}$

Several observations support a genetic predisposition to $\mathrm{CH}$. Relative risk for disease is increased, ${ }^{8}$ while pedigree analysis indicates autosomal dominant segregation, with reduced penetrance. ${ }^{18}$ Incomplete concordance for monozygotic twins with $\mathrm{CH}^{8,19}$ suggests a complex etiology with environmental involvement.
The molecular basis of $\mathrm{CH}$ remains poorly characterized. Mitochondrial mutations seen in two subjects $^{20,21}$ may be chance findings. ${ }^{22,23}$ Case-control analyses of the calcium channel gene CACNA1A and the nitric oxide synthase genes NOS1, NOS2A, and NOS3, while good biologic candidates, revealed no allelic association. ${ }^{24-28}$ Furthermore, linkage to the CACNA1A locus has been excluded in a $\mathrm{CH}$ family. ${ }^{29}$

The neuropeptides hypocretin- 1 and -2 , expressed within the posterolateral hypothalamus, ${ }^{30}$ activate the hypocretin receptor 2 (HCRTR2) and regulate the sleep-wake cycle, with hypocretin system deficiencies associated with narcolepsy. ${ }^{31}$ A recent study in Italian sporadic patients identified a single HCRTR2 polymorphism associated with $\mathrm{CH} .{ }^{32}$ Here, we present results from a genome-wide scan in $\mathrm{CH}$ families and seek replication of association to the HCRTR2 gene.

Methods. Familial Danish, Italian, and Swedish $\mathrm{CH}$ patients were ascertained as described previously. ${ }^{18,33,34}$ Danish probands, recruited from two neurologic clinics by a single investigator

\section{See also page 1917}

From the Division of Medical Genetics (L.B., H.H., R.C.T.), University of Leicester, UK; Department of Neurology (C.S., J.H.), Karolinska Institute, Karolinska University Hospital, Huddinge, Sweden; Carlo Besta National Neurological Institute (M.L., G.B.), Milan, Italy; Head and Neck Research Group, Akershus University Hospital, and Faculty Division, Akershus University Hospital (M.B.R.), University of Oslo, Norway; and Division of Medical \& Molecular Genetics (L.B., R.C.T.), King's College London (Guy's Campus), Guy's Hospital, London, UK.

Disclosure: The authors report no conflicts of interest.

Received July 26, 2005. Accepted in final form March 10, 2006.

Address correspondence and reprint requests to Dr. Richard C. Trembath, Professor of Medical Genetics, Division of Medical \& Molecular Genetics, King's College London Medical School (Guy's Campus), Floor 7, Guy's Tower, Guy's Hospital, London SE1 9RT, UK; e-mail: richard.trembath@genetics.kcl.ac.uk 
Table 1 Clinical characteristics of the cluster headache (CH) case-control cohort

\begin{tabular}{lcccc}
\hline Cases & Danish & Italian & Swedish & UK \\
\hline Sporadic cases, n & 96 & 11 & 100 & 63 \\
$\quad$ No. of chronic CH & 6 & 4 & 4 & N/K \\
No. of episodic CH & 90 & 7 & 96 & N/K \\
Male & 65 & 9 & 76 & 43 \\
Female & 31 & 2 & 24 & 20 \\
$\quad$ Mean age at onset, & $31.8(5-65)$ & $23.9(18-36)$ & $29.7(11-63)$ & N/K \\
$\quad$ y (range) & & & & \\
Control subjects, n & 72 & 0 & 106 & 89 \\
$\quad$ Male & 50 & - & 68 & 47 \\
Female & 22 & - & 38 & 42 \\
\end{tabular}

Distinction between chronic and episodic $\mathrm{CH}$ and details of age at onset were not recorded for the UK cohort.

$\mathrm{N} / \mathrm{K}=$ not known

(M.B.R.) and through the Danish patient organization for $\mathrm{CH}$, were asked to complete a mailed questionnaire detailing any known family history. Patients of Italian origin, ascertained through the Headache Centre of the Carlo Besta National Neurologic Institute, all underwent physical and neurologic examination including cerebral CT or MRI to exclude secondary headache. Swedish CH patients were collected at the Department of Neurology, Huddinge University Hospital, or via the $\mathrm{CH}$ network on the Swedish migraine patients' Web site (Svenska Migränförbundet; http://www.migran.org/), and all affected subjects were clinically examined by a neurologist specialized in headache (C.S.). At all three centers, probands and their relatives were interviewed either directly or by telephone to establish a family history of $\mathrm{CH}$. The UK subjects were recruited via the Organisation for the Understanding of Cluster Headaches in the UK (OUCH [UK]; http:// www.clusterheadaches.org.uk/). Criteria used for diagnosis of $\mathrm{CH}$ were consistent between each of the four countries and were as specified by the International Classification of Headache Disorders. ${ }^{2}$ Peripheral blood samples were taken from all consenting familial $\mathrm{CH}$ patients $(\mathrm{n}=167 ; 69$ Danish, 43 Italian, 50 Swedish, and $5 \mathrm{UK}$ ) and their healthy relatives.

$\mathrm{CH}$ singletons used in the HCRTR2 association analysis were ascertained in the same way as familial cases, but reported no family history of the condition. Control subjects, matched for ancestry, were drawn from the general population (Denmark) or consisted of blood donors, healthy volunteers, or spouses of probands (Sweden and UK). Table 1 summarizes the clinical characteristics of the case-control cohort.

All patient and control populations were of Caucasian origin. The study was approved by the relevant local ethics committees and all participants gave informed consent prior to the study.

DNA extraction and genotyping. Genomic DNA was extracted from $10 \mathrm{~mL}$ of peripheral venous blood using standard techniques. A genome-wide screen was performed for individuals from five multigenerational Danish families, using fluorescently labeled microsatellite markers with an average spacing of $9 \mathrm{cM}$ (Marshfield Center for Medical Genetics, screening set v10). PCR amplifications were performed on MJ Research DNA Engines $(10 \mu \mathrm{L}$ reactions; $50 \mathrm{ng}$ DNA, $1.5 \mathrm{mM} \mathrm{MgCl}_{2}, 0.2 \mathrm{mM}$ dNTPs [Pharmacia], 0.2 $\mu \mathrm{M}$ each primer, 0.5 U Taq polymerase [ABgene] in a $10 \times \mathrm{KCl}$ PCR buffer [ABgene]). PCR products were pooled and electrophoresed through 6\% polyacrylamide gels (Flowgen) on an ABI 377 DNA sequencer. Genotype data were generated using GeneScan v3.0 and Genotyper v2.1 software (Applied Biosystems). Data for 21 markers that failed to optimize were excluded from further analysis. Typing was successful for $95 \%$ of genotypes at the remaining 383 markers (full details available on request to author). Data for the X and Y chromosomes were used to confirm pedigree structures but were not included in linkage analyses, as the frequency of affected females and presence of male-to-male transmission were considered inconsistent with a sex-linked model of inheritance.

Following statistical analysis of the genome screen data, further markers (D2S2299, D2S142, D2S2380, D2S111, D2S130,
Table 2 Clinical characteristics of cluster headache (CH) kindreds used in linkage analyses

\begin{tabular}{|c|c|c|c|}
\hline & $\begin{array}{l}\text { Danish } \\
\text { cohort }\end{array}$ & $\begin{array}{l}\text { Italian } \\
\text { cohort }\end{array}$ & Total \\
\hline No. of families & 21 & 12 & 33 \\
\hline $\begin{array}{l}\text { Total no. of individuals } \\
\text { genotyped }\end{array}$ & 125 & 37 & 162 \\
\hline $\begin{array}{l}\text { Mean no. of subjects per } \\
\text { family (range) }\end{array}$ & $6.0(2-15)$ & $3.1(2-7)$ & $4.9(2-15)$ \\
\hline $\begin{array}{l}\text { Total no. of affected subjects } \\
\text { genotyped }\end{array}$ & 56 & 26 & 82 \\
\hline $\begin{array}{l}\text { Mean no. of affecteds per } \\
\text { family (range) }\end{array}$ & $2.7(2-6)$ & $2.2(2-4)$ & $2.5(2-6)$ \\
\hline Total no. of chronic $\mathrm{CH}$ cases & 6 & 0 & 6 \\
\hline Male & 3 & - & 3 \\
\hline Female & 3 & - & 3 \\
\hline Mean age at onset, y (range) & $35(18-56)$ & - & $35(18-56)$ \\
\hline Total no. of episodic CH cases & 50 & 26 & 76 \\
\hline Male & 37 & 17 & 54 \\
\hline Female & 13 & 9 & 22 \\
\hline Mean age at onset, $\mathrm{y}$ (range) & $26.1(7-52)$ & $23.5(10-50)$ & $25.2(7-52)$ \\
\hline
\end{tabular}

D2S2390，D2S401，D2S2213，D8S1755，D8S552，D8S1827, D8S1731, D9S288, D9S1810, D9S281, and D9S286), selected from genetic maps at the Marshfield Center for Medical Genetics (http://research.marshfieldclinic.org/genetics/Map_Markers/maps/ IndexMapFrames.html), were typed for those loci showing evidence of potential linkage. At this stage of analysis, the cohort was supplemented by inclusion of newly available material, namely a further 8 family members (3 affected) from families D42, D162, and D651, plus 111 additional individuals (60 affected) from 16 Danish and 12 Italian kindreds. Table 2 summarizes the characteristics of all $\mathrm{CH}$ kindreds used in linkage analyses.

For the SNP genotyping, DNA samples were arranged into 96-well microtiter plates, comprising 259 unrelated sporadic $\mathrm{CH}$ patients and 267 ethnically matched control subjects. Patients of Italian origin were omitted from the HCRTR2 association analysis due to the small sample size and lack of a suitable control population (see table 1). Two polymorphisms of the HCRTR2 gene (rs3122169 and rs2653349 from NCBI dbSNP; http://www.ncbi. nlm.nih.gov/SNP/) were amplified from plated DNA samples using sequence-analysis primers for exons 2 and 5, and resultant products were dot-blotted onto Hybond N (Amersham). SNPs were typed by ASO hybridization using a tetramethylammonium chloride (TMAC) hybridization protocol. ${ }^{35}$ Alleles were assigned by direct examination of autoradiographs compared for each allele.

HCRTR2 sequencing. The complete protein-coding region and intron/exon boundaries, including splice donor/acceptor sites, $3^{\prime}$ UTR, and $200 \mathrm{bp}$ of flanking $5^{\prime}$ UTR, of the HCRTR2 gene were amplified by PCR in $40 \mu \mathrm{L}$ reactions for an affected subject from each of eight independent families, namely D42, D162, ITA6, ITA48, SWE13, SWE14, UK1, and UK5, plus one normal control individual. PCR products were separated by electrophoresis through $2 \%$ LE agarose (FMC Bioproducts) to ensure the presence of sufficient quantities for sequence analysis, and were then purified using the QIAquick PCR purification kit (Qiagen). Purified PCR products were sequenced with the Applied Biosystems BigDye terminator kit, and were electrophoresed through 5\% LongRanger (Cambrex) polyacrylamide gels on an ABI 377 automated sequencer (Applied Biosystems). Sequence traces were analyzed with Sequence Analysis v3.2 and SeqEd v1.0.3 computer software (Applied Biosystems).

Statistical analyses. Family-based data were first analyzed using the simulation program SLINK, ${ }^{36,37}$ to establish the cumulative power to detect significant evidence for linkage contained in the five largest Danish families (D42, D150, D162, D651, and D799). These families were selected as they consisted of three or more affected individuals, distributed across at least one generation. Marker data were generated randomly for 1,000 replications, and simulated datasets analyzed under a disease model of autosomal dominant inheritance with a reduced penetrance of $30 \%$. A 
disease allele frequency of 0.001 and a phenocopy rate of 0.001 were assigned. Simulations were performed in duplicate, assuming locus homogeneity and heterogeneity, with percentages of linked families designated at $100 \%$ and $70 \%$.

The computer program GAS (Genetic Analysis System v2.0; Alan Young, Oxford 1993-1995) was used to format genotype data for linkage analysis, to verify inheritance, and to calculate marker allele frequencies. Any identified inconsistencies were corrected by re-assessment of original GeneScan files and, if necessary, regenotyping. If anomalies could not be resolved after a second round of genotyping, data for all family members were removed to avoid potential biasing.

Single- and multipoint linkage analyses were performed using Genehunter v2.1. ${ }^{38}$ lod Scores were calculated using the disease model described above. Due to potential ambiguity for the mode of transmission in $\mathrm{CH}$, Genehunter was also used to generate modelfree nonparametric NPL scores for each analysis. For those loci reaching a lod or NPL score of 2.0 or above, corresponding to the criteria of potentially interesting ${ }^{39}$ four additional markers spanning each locus with an average spacing of $2 \mathrm{cM}$ were next analyzed.

Association analysis of HCRTR2 SNP data were assessed using a $\chi^{2}$ test, to compare both allele and genotype frequencies between case and control populations. Hardy-Weinberg equilibrium was observed in $\mathrm{CH}$ cases and controls and significance was established at $p<0.01$.

Results. Linkage analysis. We chose five extended kindreds to perform simulations of linkage using the SLINK program. Estimates of the maximum lod score, based on all markers and subjects being informative, achieved values of 3.35 and 3.17, under models of disease locus homoand heterogeneity. Furthermore, the likelihood of reaching a combined lod score of $>3$ by chance alone was calculated as $1.6 \%$ of the replicates, which decreased to $0.2 \%$ if a model of more than one disease locus for $\mathrm{CH}$ was applied.

Using real genotype data, we performed single- and multipoint linkage analyses to generate lod and NPL scores for each autosome. The results from the complete genome screen gave no significant support for linkage to a single chromosomal region. However, lod and NPL scores either potentially interesting or suggestive of linkage $(\geq 2.0)$ were obtained for two distinct loci on chromosome 2 (markers D2S1353; $164.51 \mathrm{cM}$, and D2S1363; $227.0 \mathrm{cM}$ ), and one locus on each of chromosome 8 (GATA151F02; $27.4 \mathrm{cM}$ ) and chromosome 9 (D9S2169; $14.23 \mathrm{cM}$ ). The figure illustrates the two-point lod and NPL scores combined with the multipoint linkage analyses.

For each of the loci demonstrating potential linkage, four additional markers were typed and genotype data analyzed for the whole chromosome to extract maximum information from the Genehunter analysis package. Of the four loci examined, inclusion of additional markers maintained support of potential linkage at the GATA151F02 locus on chromosome 8 alone. Multipoint linkage analysis generated NPL scores over 2.0 for three of the four flanking markers $\left(\mathrm{NPL}_{\max }=2.32\right.$ for distal marker D8S1827). Single point analysis failed to support linkage to newly typed markers flanking any of the initial loci investigated.

Genotype data for each of the four distinct potentially linked loci were next analyzed in 60 further subjects, ascertained primarily as nuclear kindreds with two or more affected individuals. Pedigrees were subdivided into Danish and Italian cohorts, to establish whether individual populations provided evidence of linkage to distinct loci, before repeating the analyses for the combined dataset. The Danish cohort (consisting of families D42 to D799 plus 16 new pedigrees) provided no evidence of linkage to any of

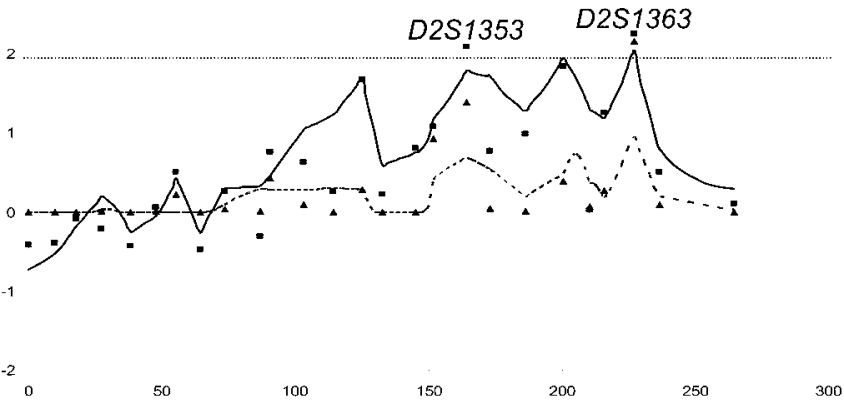

Chromosome 8

3

GATA151F02

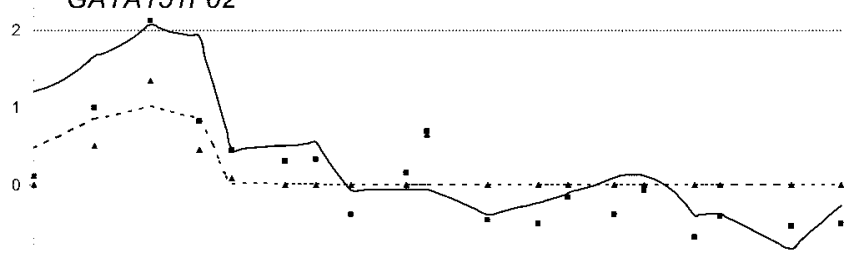

$-1$

$\begin{array}{lllllllll}2 & 20 & 40 & 60 & 80 & 100 & 120 & 140 & 160\end{array}$

Chromosome 9

3

D9S2169

2 …....

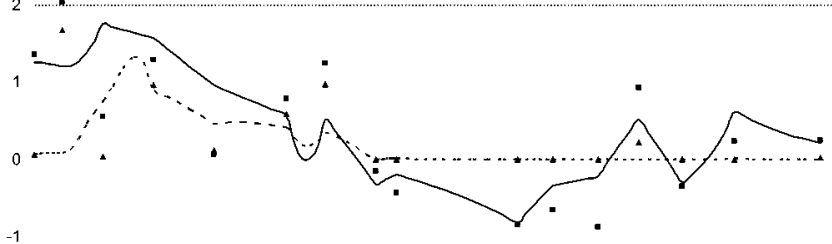

$-2$

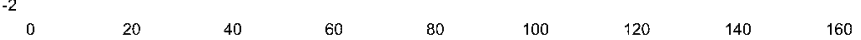

Figure. Graphs illustrating results of chromosome specific linkage analyses from genome-wide scan. Data identifying regions of potential linkage (designated as NPL/lod $\geq 2.0$ ) are displayed, with distance along the chromosome in centiMorgans ( $x$-axis) and lod/NPL score (y-axis). Solid lines represent multipoint NPL scores; dashed lines, multipoint lod scores. Filled squares illustrate two-point NPL scores; filled triangles, two-point lod scores.

the identified loci, generating a maximum combined multipoint NPL score of 1.82 at D8S1827, and a maximum single point NPL of 1.41 for GATA151F02. In contrast, analysis of a small Italian cohort generated compelling support for linkage to chromosome 9, with multipoint NPL scores of 2.19 and 2.41 ( $p=0.0098$ ) for markers D9S2169 and D9S281 observed. These scores were not maintained when Danish and Italian populations were combined.

Mutation analysis and association study of HCRTR2. To determine whether a pathogenic mutation of the HCRTR2 gene might explain the familial occurrence of $\mathrm{CH}$ in our kindreds, we performed sequencing of 
Table 3 Genotype and allele frequencies of HCRTR2 single nucleotide polymorphisms in the complete cohort

\begin{tabular}{|c|c|c|c|c|c|c|c|c|c|c|}
\hline & \multirow[b]{2}{*}{$\mathrm{n}$} & \multicolumn{3}{|c|}{$\mathrm{GF}(\%)$} & \multirow[b]{2}{*}{$\chi^{2}$} & \multirow[b]{2}{*}{$p$ Value } & \multicolumn{2}{|c|}{$\mathrm{AF}(\%)$} & \multirow[b]{2}{*}{$x^{2}$} & \multirow[b]{2}{*}{$p$ Value } \\
\hline & & AA & $\mathrm{AC}$ & $\mathrm{CC}$ & & & $\mathrm{A}$ & $\mathrm{C}$ & & \\
\hline \multicolumn{11}{|c|}{ c.224-26A >C [rs3122169] } \\
\hline $\mathrm{CH}$ patients & 258 & $172(66.7)$ & $80(31.0)$ & $6(2.3)$ & $2.86 *$ & 0.239 & 424 (82) & $92(18)$ & $0.273 \dagger$ & 0.603 \\
\hline Controls & 238 & $159(66.8)$ & $67(28.2)$ & $12(5.0)$ & & & $385(81)$ & $91(19)$ & & \\
\hline c. $922 \mathrm{G}>\mathrm{A}[\mathrm{rs} 2653349]$ & & GG & GA & AA & & & $\mathrm{G}$ & $\mathrm{A}$ & & \\
\hline $\mathrm{CH}$ patients & 257 & $165(64.2)$ & $84(32.7)$ & $8(3.1)$ & $2.73^{*}$ & 0.255 & $414(81)$ & $100(19)$ & $1.80 \dagger$ & 0.180 \\
\hline Controls & 267 & $161(60.3)$ & 90 (33.7) & $16(6.0)$ & & & $412(77)$ & $122(23)$ & & \\
\hline
\end{tabular}

* Two degrees of freedom.

$\dagger$ One degree of freedom.

$\mathrm{GF}=$ genotype frequencies; $\mathrm{AF}=$ allele frequencies.

genomic DNA for a single affected subject (total $\mathrm{n}=8$ ) from each of two independent families of Danish, Italian, Swedish, and British origin. No deleterious sequence variants were detected by comparison to wild-type control sequence.

Table 3 shows the genotype and allele frequencies observed for each of the HCRTR2 single nucleotide polymorphisms examined. For the intronic SNP [rs3122169] we detected no significant difference in allele or genotype frequencies between the patient and control populations, using a $\chi^{2}$ test of probability. Results for the 922G/A polymorphism in exon 5 [rs2653349], previously reported to be associated with $\mathrm{CH}$, showed no difference in either genotype or allele frequencies in our diverse $\mathrm{CH}$ cohort, when compared with a matched control population. To establish whether the tested polymorphisms showed an association with $\mathrm{CH}$ in individual cohorts, the same data were stratified into distinct populations. Again, we detected no significant difference for either genotype or allele frequencies between $\mathrm{CH}$ patients and ethnically matched controls (table 4). Further stratification by sex, taking into account the sex bias observed in $\mathrm{CH}$, also provided no support for association (data not shown).

Discussion. Anticipating the complexity of inherited predisposition to $\mathrm{CH}$, we initiated a European collaboration to pool material from probands, sibships, and multiplex extended kindred ascertained across Northern Europe. To date, this cohort comprises subjects ascertained from 84 independent kindreds with $\mathrm{CH}$ (167 affected subjects) and 270 sporadic $\mathrm{CH}$ cases. In this study, we sought to identify gene locations implicated in disease predisposition by performing a medium $(9 \mathrm{cM})$ density genomewide scan. In addition, we sought replication of a specific candidate gene identified through an association study.

We assessed five multiplex kindreds, each of Danish origin, using a parametric model of a $\mathrm{CH}$ gene acting as an autosomal dominant trait with $30 \%$ penetrance. No significant lod scores were identified for any locus across the genome. We next performed a model-free (nonparametric) based analysis, and identified potentially interesting scores for four loci, namely chromosome 2, D2S1353; chromosome 2, D2S1363; chromosome 8, GATA151F02; and chromosome 9, D9S2169. To further interrogate these regions of putative interest, we next studied an extended collection of Danish and Italian kindreds, together with additional independent subjects. We typed further STS markers for each region and, despite adequate power to detect linkage under assumptions of homogeneity, no single locus reached significance. In conclusion, we were unable to specify

Table 4 Stratification of SNP data into ascertainment populations

\begin{tabular}{|c|c|c|c|c|c|c|c|c|c|c|c|c|}
\hline & \multicolumn{6}{|c|}{ c.224-26A >C [rs3122169] } & \multicolumn{6}{|c|}{ c. $922 \mathrm{G}>\mathrm{A}[\mathrm{rs} 2653349]$} \\
\hline & \multirow[b]{2}{*}{$\mathrm{n}$} & \multicolumn{3}{|c|}{$\mathrm{GF}(\%)$} & \multicolumn{2}{|c|}{$\mathrm{AF}(\%)$} & \multirow[b]{2}{*}{$\mathrm{n}$} & \multicolumn{3}{|c|}{$\mathrm{GF}(\%)$} & \multicolumn{2}{|c|}{$\mathrm{AF}(\%)$} \\
\hline & & AA & $\mathrm{AC}$ & $\mathrm{CC}$ & $\mathrm{A}$ & $\mathrm{C}$ & & GG & GA & AA & G & $\mathrm{A}$ \\
\hline \multicolumn{13}{|l|}{ Danish cohort } \\
\hline $\mathrm{CH}$ patients & 96 & $61(63.5)$ & $33(34.4)$ & $2(2.1)$ & $155(81)$ & $37(19)$ & 96 & $56(58.3)$ & $38(39.6)$ & $2(2.1)$ & $150(78)$ & $42(22)$ \\
\hline Controls & 69 & $40(58.0)$ & $26(37.7)$ & $3(4.3)$ & $106(77)$ & $32(23)$ & 72 & $37(51.4)$ & $31(43.1)$ & $4(5.6)$ & $105(73)$ & $39(27)$ \\
\hline \multicolumn{13}{|l|}{ Swedish cohort } \\
\hline $\mathrm{CH}$ patients & 99 & $72(72.7)$ & $24(24.2)$ & $3(3.0)$ & $168(85)$ & $30(15)$ & 98 & $68(69.4)$ & $26(26.5)$ & $4(4.1)$ & $162(83)$ & $34(17)$ \\
\hline Controls & 84 & $60(71.4)$ & $19(22.6)$ & $5(6.0)$ & $139(83)$ & $29(17)$ & 106 & $67(63.2)$ & $32(30.2)$ & $7(6.6)$ & $166(78)$ & $46(22)$ \\
\hline \multicolumn{13}{|l|}{ UK cohort } \\
\hline $\mathrm{CH}$ patients & 63 & $39(61.9)$ & $23(36.5)$ & $1(1.6)$ & $101(80)$ & $25(20)$ & 63 & $41(65.1)$ & $20(31.7)$ & $2(3.2)$ & $102(81)$ & $24(19)$ \\
\hline Controls & 85 & $59(69.4)$ & $22(25.9)$ & $4(4.7)$ & $140(82)$ & $30(18)$ & 89 & $57(64.0)$ & $27(30.3)$ & $5(5.6)$ & $141(79)$ & $37(21)$ \\
\hline
\end{tabular}

$\mathrm{GF}=$ genotype frequencies; $\mathrm{AF}=$ allele frequencies. 
a solitary disease locus for the $\mathrm{CH}$ phenotype using the available dataset.

$\mathrm{CH}$ rarely occurs in families as a monogenic trait and our data might suggest locus heterogeneity underlying inherited predisposition to familial $\mathrm{CH}$. This observation would parallel similar findings in other forms of genetically determined headache. For example, molecular genetic studies have identified mutations in at least two causative genes, CACNA1A and $A T P 1 A 2$, in familial hemiplegic migraine, a rare autosomal dominant form of migraine associated with aura. ${ }^{24,40}$ However, recent genome-wide screens in common migraine suggest other, as yet uncharacterized, genes may contribute to this group of disorders, with identification of susceptibility loci on chromosomes 4q, 6p12.2-p21.1, 11q24, 14q21.2$\mathrm{q} 22.3,15 \mathrm{q} 11-\mathrm{q} 13$, and Xq24-q28, ${ }^{41,42}$ together with evidence of suggestive linkage to chromosomes $3 \mathrm{q}$ and $18 \mathrm{p} 11 .^{43}$

The discovery that inherited forms of headache can develop through disruption of specific ion channels provides important insight as to mechanistic defects of potential relevance to $\mathrm{CH}$ and thereby suggest numerous candidate genes and loci for examination. However, a number of clinical features and characteristics typical of $\mathrm{CH}$ suggest the likely involvement of alternative pathways underlying disease predisposition. For example, the periodicity of attacks implies a potential defect within the suprachiasmatic nucleus of the hypothalamus, a key neurogenic regulator of the human biologic clock and which has been shown to become activated during a cluster attack..$^{10}$ Furthermore, the severity of pain associated with $\mathrm{CH}$ compared to other types of headache might suggest a unique pathophysiology for this disorder. A recent report of association between a polymorphism in the hypocretin receptor gene, HCRTR2, in a cohort of sporadic $\mathrm{CH}$ patients ascertained within Italy, might provide additional evidence for the role of genetic factors in disease predisposition. ${ }^{32}$ However, there is now compelling evidence that initial candidate gene association studies carry a high likelihood of false-positive results, an observation that stresses the need for balanced publication of replication studies that might (rarely) confirm or (commonly) reject novel association results. ${ }^{44}$ Here we examined two polymorphisms which include the associated coding sequence variant $($ c.922G $>$ A) in a larger sample size, with greater than $95 \%$ power to detect association under identical conditions of replication. We detected no significant support for allelic association at the HCRTR2 locus. Stratification of association data into discrete populations failed to yield evidence for association of either SNP with $\mathrm{CH}$. Furthermore, we found no evidence of linkage to chromosome $6 \mathrm{p} 12.1$ within our family based genome-wide scan. Finally, we performed sequence analysis of genomic DNA for the entire coding region of HCRTR2 in eight probands from $\mathrm{CH}$ families and detected no pathogenic sequence variants. Hence, and in contrast to the origi- nal report, we find no evidence for even marginal effects of variants within the HCRTR2 gene in the European cohorts investigated here. However, our study cannot exclude the possibility that other variants may be either disease causing or in linkage disequilibrium with disease causing variants that are specific to one or more populations. In this regard, it should be noted that the association analysis did not include any subjects ascertained in Italy as we do not have an adequate population-based control cohort for that region. The potential for hidden population stratification as an explanation for the conflicting results from the studies looking at association between HCRTR2 and $\mathrm{CH}$ is further underlined when we note the marked variation in allele frequencies of this gene in different control cohorts (see table 4). ${ }^{32}$ At this stage of investigation into the genetic basis of $\mathrm{CH}$, our findings argue strongly for careful attention to methodologic detail. For example, further linkage studies will require large sample sizes or extended pedigrees with multiple affected subjects, ideally ascertained prospectively to deal with inherent concerns of historical records of the $\mathrm{CH}$ phenotype in previous generations. For association studies, this work adds further to the call for collaboration between centers working in this field as sample size and independent replication within a study should be the gold standard of future reports. ${ }^{45}$

This report suggests that genetic predisposition to $\mathrm{CH}$ is liable to be complex and likely compounded by locus heterogeneity and variation in genes conferring only a small effect size. Despite recent progress in therapeutic strategies for the management of $\mathrm{CH}$, a detailed understanding of the etiology and pathogenesis remains the most plausible means of comprehensive and targeted approaches to the treatment of this debilitating disorder.

\section{Acknowledgment}

The authors thank the patients and families for their participation, Dr. Elisabet Waldenlind at Karolinska University Hospital, Huddinge, for information about $\mathrm{CH}$ families and contribution to the collection of $\mathrm{CH}$ patients, and Dr. Karl Ekbom for providing information about $\mathrm{CH}$ families. The authors also thank Dr. Esther Kinning, Dr. Rachel Harrison, and Linsey Joy for help in UK patient sample collections.

\section{References}

1. Bahra A, May A, Goadsby PJ. Cluster headache: a prospective clinical study with diagnostic implications. Neurology 2002;58:354-361.

2. Headache Classification Subcommittee of the International Headache Society. The International Classification of Headache Disorders. Cephalalgia 2004;24(suppl 1):1-160.

3. Manzoni GC, Micieli G, Granella F, Tassorelli C, Zanferrari C, Cavallini A. Cluster headache course over ten years in 189 patients. Cephalalgia 1991;11:169-174.

4. Tonon C, Guttmann S, Volpini M, Naccarato S, Cortelli P, D'Alessandro R. Prevalence and incidence of cluster headache in the Republic of San Marino. Neurology 2002;58:1407-1409.

5. Sjaastad O, Bakketeig LS. Cluster headache prevalence. $\mathrm{Va}^{\circ} \mathrm{ga}^{\circ}$ study of headache epidemiology. Cephalalgia 2003;23:528-533.

6. Torelli P, Beghi E, Manzoni GC. Cluster headache prevalence in the Italian general population. Neurology 2005;64:469-474.

7. Manzoni GC. Male preponderance of cluster headache is progressively decreasing over the years. Headache 1997;37:588-589.

8. Russell MB. Epidemiology and genetics of cluster headache. Lancet Neurol 2004;3:279-283. 
9. Goadsby PJ, Edvinsson L. Human in vivo evidence for trigeminovascular activation in cluster headache. Neuropeptide changes and effects of acute attacks therapies. Brain 1994;117:427-434.

10. May A, Bahra A, Buchel C, Frackowiak RSJ, Goadsby PJ. Hypothalamic activation in cluster headache attacks. Lancet 1998;352:275-278.

11. Chazot G, Claustrat B, Brun J, Jordan D, Sassolas G, Schott B. A chronobiological study of melatonin, cortisol growth hormone and prolactin secretion in cluster headache. Cephalalgia 1984;4:213-220.

12. Waldenlind E, Ekbom K, Wetterberg L, et al. Lowered circannual urinary melatonin concentrations in episodic cluster headache. Cephalalgia 1994;14:199-204.

13. Strittmatter M, Hamann GF, Grauer M, et al. Altered activity of the sympathetic nervous system and changes in the balance of hypophyseal, pituitary and adrenal hormones in patients with cluster headache. Neuroreport 1996;7:1229-1234.

14. Leone M, Lucini V, D'Amico D, et al. Abnormal 24-hour urinary excretory pattern of 6-sulphatoxymelatonin in both phases of cluster headache. Cephalalgia 1998;18:664-667.

15. Sprenger T, Boecker H, Tolle TR, Bussone G, May A, Leone M. Specific hypothalamic activation during a spontaneous cluster headache attack. Neurology 2004;62:516-517.

16. Leone M, Franzini A, Bussone G. Stereotactic stimulation of posterior hypothalamic gray matter in a patient with intractable cluster headache. N Engl J Med 2001;345:1428-1429.

17. Franzini A, Ferroli P, Leone M, Broggi G. Stimulation of the posterior hypothalamus for treatment of chronic intractable cluster headaches: first reported series. Neurosurgery 2003;52:1095-1099.

18. Russell MB, Andersson PG, Thomsen LL, Iselius L. Cluster headache is an autosomal dominantly inherited disorder in some families: a complex segregation analysis. J Med Genet 1995;32:954-956.

19. Svensson DA, Ekbom K, Pedersen NL, Traff H, Waldenlind E. A note on cluster headache in a population-based twin register. Cephalalgia 2003;23:376-380.

20. Shimomura T, Kitano A, Marukawa H, et al. Point mutation in platelet mitochondrial tRNA(Leu(UUR)) in patient with cluster headache. Lancet 1994;344:625.

21. Odawara M, Tamaoka A, Mizusawa H, Yamashita K. A case of cluster headache associated with mitochondrial DNA deletions. Muscle Nerve 1997;20:394-395.

22. Cortelli P, Zacchini A, Barboni P, Malpassi P, Carelli V, Montagna P Lack of association between mitochondrial tRNA(Leu(UUR)) point mutation and cluster headache. Lancet 1995;345:1120-1121.

23. Seibel P, Grunewald T, Gundolla A, Diener HC, Reichmann H. Investigation on the mitochondrial transfer RNA(Leu)(UUR) in blood cells from patients with cluster headache. J Neurol 1996;243:305-307.

24. Ophoff RA, Terwindt GM, Vergouwe MN, et al. Familial hemiplegic migraine and episodic ataxia type- 2 are caused by mutations in the Ca2+ channel gene CACNL1A4. Cell 1996;87:543-552.

25. Jodice C, Mantuano E, Veneziano L, et al. Episodic ataxia type 2 (EA2) and spinocerebellar ataxia type 6 (SCA6) due to CAG repeat expansion in the CACNA1A gene on chromosome 19p. Hum Mol Genet 1997;6: 1973-1978.

26. Zhuchenko O, Bailey J, Bonnen P, et al. Autosomal dominant cerebellar ataxia (SCA6) associated with small polyglutamine expansions in the alpha 1A-voltage-dependent calcium channel. Nat Genet 1997;15:6269.

27. Sjöstrand C, Giedratis V, Ekbom K, Waldenlind E, Hillert J. CACNA1A gene polymorphisms in cluster headache. Cephalalgia 2001;21:953-958.

28. Sjöstrand C, Modin H, Masterman T, Ekbom K, Waldenlind E, Hillert J. Analysis of nitric oxide synthase genes in cluster headache. Cephalalgia 2002;22:758-764.

29. Haan J, van Vliet JA, Kors EE, et al. No involvement of the calcium channel gene (CACNA1A) in a family with cluster headache. Cephalalgia 2001;21:959-962.

30. De Lecea L, Kilduff TS, Peyron C, et al. The hypocretins: hypothalamus-specific peptides with neuroexcitatory activity. Proc Natl Acad Sci USA 1998;95:322-327.

31. Peyron C, Faraco J, Rogers W, et al. A mutation in a case of early onset narcolepsy and a generalized absence of hypocretin peptides in human narcoleptic brains. Nat Med 2000;6:991-997.

32. Rainero I, Gallone S, Valfre W, et al. A polymorphism of the hypocretin receptor 2 gene is associated with cluster headache. Neurology 2004;63: 1286-1288.

33. Leone M, Russell MB, Rigamonti A, et al. Increased familial risk of cluster headache. Neurology 2001;56:1233-1236.

34. Sjöstrand C, Russell MB, Ekbom K, Hillert J, Waldenlind E. Familial cluster headache. Is atypical cluster headache in family members part of the clinical spectrum? Cephalalgia 2005;25:1068-1077.

35. Jeffreys AJ, Ritchie A, Neumann R. High-resolution analysis of haplotype diversity and meiotic crossover in the human TAP2 recombination hotspot. Hum Mol Genet 2000;9:725-733.

36. Ott J. Computer-simulation methods in human linkage analysis. Proc Natl Acad Sci USA 1989;86:4175-4178.

37. Weeks DE, Ott J, Lathrop GM. SLINK: a general simulation program for linkage analysis. Am J Hum Genet 1990;47:A204 (suppl).

38. Markianos K, Daly MJ, Kruglyak L. Efficient multipoint linkage analysis through reduction of inheritance space. Am J Hum Genet 2001;68: 963-977.

39. Lander E, Kruglyak L. Genetic dissection of complex traits: guidelines for interpreting and reporting linkage results. Nat Genet 1995;11:241247.

40. De Fusco M, Marconi R, Silvestri L, et al. Haploinsufficiency of ATP1A2 encoding the $\mathrm{Na}+/ \mathrm{K}+$ pump alpha2 subunit associated with familial hemiplegic migraine type 2. Nat Genet 2003;33:192-196.

41. Wessman M, Kaunisto MA, Kallela M, Palotie A. The molecular genetics of migraine. Ann Med 2004;36:462-473.

42. Russo L, Mariotti P, Sangiorgi E, et al. A new susceptibility locus for migraine with aura in the 15q11-q13 genomic region containing three GABA-A receptor genes. Am J Hum Genet 2005;76:327-333.

43. Lea RA, Nyholt DR, Curtain RP, et al. A genome-wide scan provides evidence for loci influencing a severe heritable form of common migraine. Neurogenetics 2005;6:67-72.

44. Cardon LR, Bell JI. Association study designs for complex diseases. Nat Rev Genet 2001;2:91-99.

45. Neale BM, Sham PC. The future of association studies: gene-based analysis and replication. Am J Hum Genet 2004;75:353-362.

\section{DID YOU KNOW...}

. . y you can browse by subspecialty topics on www.neurology.org?

Go to: http://www.neurology.org/collections and click on the specific topic for a complete list of articles. 
A genome-wide scan and HCRTR2 candidate gene analysis in a European cluster headache cohort

L. Baumber, C. Sjöstrand, M. Leone, H. Harty, G. Bussone, J. Hillert, R. C. Trembath and M. B. Russell

Neurology 2006;66;1888-1893

DOI: 10.1212/01.wnl.0000219765.95038.d7

This information is current as of June 29, 2006

$\begin{array}{ll}\begin{array}{l}\text { Updated Information } \\ \text { \& Services }\end{array} & \begin{array}{l}\text { including high-resolution figures, can be found at: } \\ \text { http://www.neurology.org/cgi/content/full/66/12/1888 }\end{array} \\ \text { Related Articles } & \text { A related article has been published: } \\ \text { http://www.neurology.org/cgi/content/full/66/12/1792 } & \text { This article, along with others on similar topics, appears in the } \\ \text { Subspecialty Collections } & \text { All Genetics } \\ & \text { http://www.neurology.org/cgi/collection/all_genetics All } \\ & \text { Headache } \\ & \text { http://www.neurology.org/cgi/collection/all_headache Cluster } \\ \text { headache } & \text { http://www.neurology.org/cgi/collection/cluster_headache } \\ & \text { Information about reproducing this article in parts (figures, tables) } \\ & \text { or in its entirety can be found online at: } \\ \text { http://www.neurology.org/misc/Permissions.shtml } & \text { Information about ordering reprints can be found online: } \\ \text { Permissions \& Licensing } & \text { http://www.neurology.org/misc/reprints.shtml }\end{array}$

\section{AMERICAN ACADEMY OF NEUROLOGY}

